\title{
Usos y abusos de la prensa como fuente de datos sobre acciones colectivas
}

\author{
MANUEl A. Río \\ Universidad de Sevilla \\ manurio@us.es
}

Recibido: 13.02 .2008

Aceptado: 04.11.2008

\section{INTRODUCCIÓN}

En el campo de la sociología de la acción colectiva y de los movimientos sociales ha venido siendo habitual el recurso a los periódicos como fuente de localización, registro y análisis de eventos en los que individuos y grupos, alineados en torno a divisorias étnicas, de clase, u otras formas de asociación, expresan o materializan un desafío frente a otros grupos y/o las autoridades. La frecuente ausencia a la hora de realizar este tipo de estudios de otras fuentes continuadas de datos alternativas a los diarios, las cuales permitirían también la recopilación de grandes catálogos de protestas sociales dispersas en el espacio y en el tiempo, ha provocado excesos en el uso que se hace de la prensa. Los mismos han contribuido a minar la, ya de por sí escasa, aceptación de estas fuentes para la investigación social.

Este artículo resume las limitaciones, pero también algunas ventajas, de la prensa como fuente de datos para estudios sobre protestas sociales, como el que constituyó mi tesis doctoral. En la misma analizaba las pautas de desarrollo - interacciones entre los participantes, tácticas aplicadas, secuencias del conflicto, etc.- de los centenares de casos que conforman el repertorio de protestas populares contra los realojos y escolarizaciones de poblaciones gitanas en la España posfranquista (Río Ruiz, 2005). Buena parte de aquel trabajo consistió en buscar fuentes en las que pudieran localizarse referencias a movilizaciones antigitanas de manera abundante, clara y uniforme. Y en abstraer de las mismas la información relativa a cada uno de los episodios de acción, determinando a su vez qué eventos de los localizados reunían las propiedades fijadas mediante la definición de las unidades de análisis. Dado que pretendía abarcar un marco temporal y espacial amplio - veinticinco años de historia de etnicismo movilizado contra comunidades gitanas a lo largo del territorio nacional— la combinación 
de prensa local y nacional —en ausencia de fuentes alternativas con un registro continuado de episodios etnicistas, al menos en España— constituyó mi principal (si bien no única) fuente de datos.

Las páginas siguientes representan el producto de una reflexión metodológica más general realizada a partir de aquella experiencia de investigación, la cual me obligó a adentrarme en la literatura existente sobre el uso de la prensa como fuente de datos sociohistóricos. En la primera parte, tras hacer referencia a algunos reconocidos estudios sobre protestas sociales que utilizaron la prensa, se apuntan algunas de las ventajas que la literatura metodológica revisada atribuye a la explotación de periódicos. Se expone que algunos de los datos sobre la acción colectiva reportados en los periódicos de manera estandarizada, no necesariamente presentan mayores problemas de fiabilidad que los extraídos de otras fuentes secundarias en las que, a veces, también podemos encontrar información sobre protestas sociales. De hecho, se sostiene que se exagera mucho a la hora de plantear las distorsiones sistemáticas de la «realidad» y de los «hechos» que produce la prensa, si bien la literatura crítica sobre las dinámicas de la producción y selección de noticias - la llamada news-making research, donde destaca la «teoría de los encuadres noticiosos»- ha establecido una gama importante de precauciones a tener muy en cuenta siempre que nos arriesguemos a utilizar periódicos para análisis de movilizaciones.

En cambio, en su segunda parte el artículo expone algunos de los problemas que se dan a la hora de la explotación de la prensa. Se incide sobre todo en la limitada validez externa de los datos obtenidos, así como en la imposibilidad de determinar la incidencia social real de un fenómeno de movilización mediante la explotación de periódicos. Y ello por mucho que a la revisión sistemática de más de un diario nacional se sume la explotación de prensa local, así como el «buceo» en otras fuentes continuadas de datos. Estrategias que muchas veces se recomiendan como medios de mitigar o controlar los sesgos asociados a las fuentes de prensa.

\section{LA PRENSA, EL «ANÁLISIS DE EVENTOS», Y LA SOCIOLOGÍA DE LA ACCIÓN COLECTIVA: UNA CIERTA TRADICIÓN}

Los historiadores ${ }^{1}$ acostumbran a tener razón cuando reprochan a los sociólogos que sólo la carencia de otras fuentes secundarias, especialmente la ausencia de estadísticas o registros oficiales, nos lleva hasta las hemerotecas. En Sociología hemos tendido a utilizar la prensa «como una fuente marginal, informal y complementaria de datos, en vez de como fuente principal» (Franzosi, 1987: 6). Solemos además mantener ante la misma un grado de prevención o vigilancia epistemológica que, en cambio, no es tan habitual que se despliegue respec-

${ }^{1}$ A fin de aligerar un poco la lectura emplearé el genérico no femenino, pero aclaro que me estaré refiriendo en todo momento a personas de ambos géneros.

EMPIRIA. Revista de Metodología de Ciencias Sociales. N. ${ }^{\circ}$ 16, julio-diciembre, 2008, pp. 59-84. ISSN: 1139-5737 
to al uso de otras fuentes secundarias como los archivos policiales o las fuentes sobre huelgas, por ejemplo ${ }^{2}$. Por lo general, aquellos estudios empíricos que se anuncian en sociedad científica - ante consejos editoriales, tribunales de tesis, etc. - como sustentados en datos procedentes de periódicos concitan de antemano una serie de predecibles y generalizadas sospechas relativas (sobre todo) a la fiabilidad de la información, tendiéndose a problematizar la naturaleza y condiciones de producción de ese tipo de datos bastante más que la de aquellos datos extraídos de otras fuentes secundarias mejor reconocidas ${ }^{3}$.

Existe, no obstante, un campo de estudios sociológicos, el de la protesta social y la acción colectiva, donde sí resulta constatable toda una tradición de investigaciones sustentadas en la explotación sistemática de datos de la prensa, bien como único recurso, bien en combinación con otras fuentes secundarias. En dicho campo, las primeras investigaciones basadas en la explotación de periódicos se centraron en las causas y pautas de las oleadas de disturbios raciales norteamericanos de los sesenta (Lieberson y Silverman, 1965; Spilerman, 1970). Estudios más recientes han mantenido el recurso a diarios como principal fuente de datos y de localización de conflictos raciales, si bien han desmontado buena parte de los hallazgos de aquellas pioneras investigaciones (Olzak et. al., 1994; Myers, 1997). A su vez, grandes catálogos de eventos registrados en diferentes periódicos a lo largo de décadas también han servido para la comparación internacional de diferentes variedades de violencia civil (Gurr, 1968; Tilly et. al., 1997), así como para el análisis de revueltas campesinas (Paige, 1975; Jenkins y Perrow, 1977) y repertorios huelguísticos (Shorter y Tilly, 1985). Además, en prensa se han sustentado importantes estudios sobre «ciclos de acción colectiva», como el «otoño caliente» italiano sacudido por la aplicación de diversas fórmulas de movilización a cargo de obreros y estudiantes (Tarrow, 1988).

Varias razones explicarían esta larga aceptación y asiduidad del recurso a la prensa que distinguiría a la sociología de la acción colectiva, al menos en relación a otras especialidades dentro de la disciplina donde la prensa no es más que una posible fuente de datos sistemáticamente descartada o utilizada de manera marginal. Por un lado, los periódicos suplen la ausencia de fuentes documentales alternativas para el análisis de algunos tipos de conflictos sociales (disturbios, motines, etc.). Por otro lado, abren la posibilidad de reunir datos sobre grandes

${ }^{2}$ Así, autores que han evaluado y comparado los sesgos de los archivos policiales y los de la prensa, sostienen que, si bien los datos de los registros policiales ayudan a neutralizar algunos sesgos de cobertura de la prensa, «no son nunca recomendables como única fuente [...] Como producto de las prácticas selectivas de una agencia administrativa, con sus propios códigos (legales), los datos policiales apenas pueden ser representativos de la gama completa de manifestaciones» (Barranco y Wisler, 1999: 302 y 310). Para una discusión similar sobre los problemas que también se dan con los registros y catálogos de datos sobre huelgas, ver Shalev (1978).

${ }^{3}$ Fuentes que, no obstante, comparten con la prensa algunos problemas. Véase, González (1994) para una síntesis de problemáticas comunes, y precauciones a tomar, a la hora de explotar «datos ya disponibles». 
corpus de casos dispersos en el espacio y en el tiempo, permitiendo esto el seguimiento de la evolución - ya veremos bajo qué limitaciones- de un determinado repertorio de acción colectiva ${ }^{4}$.

Trabajos como los citados en este apartado ${ }^{5}$ se inscriben en una estrategia de investigación más amplia: el «análisis de eventos». Estrategia consistente en el desarrollo de un conjunto de reglas y exigencias, entre ellas la delimitación precisa de las unidades de análisis y de las equivalencias entre constructos teóricos e indicadores empíricos, con el objetivo de localizar, registrar, triangular y analizar la información disponible sobre ciertas formas de acción colectiva localizada a lo largo del tiempo en «registros de archivos, periódicos, documentos históricos, y registros policiales y judiciales [...], los cuales proporcionan información sobre aspectos como la duración del evento, el número de participantes, y los resultados de la acción colectiva [...], permitiendo la recogida de la información en dimensiones conmensurables y la comparación a través de sistemas sociales o periodos de tiempo» (Olzak, 1989: 119-120).

\section{VENTAJAS DEL RECURSO A LA PRENSA}

Quienes han sustentado sus investigaciones en la explotación de periódicos suelen coincidir en señalar una serie de ventajas de la prensa para analizar la protesta social. Veamos.

Se incide en que, con frecuencia, los periódicos constituyen la única fuente documental con información sistemática sobre un fenómeno, de modo que el descarte de los mismos limita el conocimiento sobre las propiedades de sucesos para cuyo estudio no existen otras fuentes secundarias alternativas (Tilly, 1969; Olzak, 1989). Viene ocurriendo esto, por ejemplo, con los eventos etnicistas acontecidos en España. Sucesos para cuyo estudio carecemos de cualquier otra fuente de registro continuada, a diferencia de lo que ocurre desde hace décadas en países como Gran Bretaña que sí cuentan con registros oficiales —no exentos

${ }^{4}$ Cabría objetar que la mayor parte de los estudios sobre protestas sociales que utilizan la prensa tienden a reducir las cuestiones metodológicas a reducidos apéndices», cuando no a marginales notas al pie. Ahora bien, lo que al menos sí han propiciado investigaciones como las citadas ha sido un debate sobre la validez y fiabilidad de los datos de tales estudios. Discusión plasmada desde los setenta en una variedad de artículos metodológicos (Danzger, 1975; Snyder y Kelly, 1977; Kielbowicz y Scherer, 1986; Franzosi, 1987; Olzak, 1989; McCarthy et al, 1996, Hocke, 1998; Rucht y Neidhardt, 1998; Barranco y Wisler, 1999; Oliver y Myers, 1999; Myers y Caniglia, 2004). El repaso a esta literatura sugiere una línea de reflexión sobre los problemas y ventajas de la prensa, a la cual pretende contribuir este artículo de un tema apenas abordado en revistas de Ciencias Sociales españolas.

${ }^{5}$ Podrían, tal vez deberían, citarse muchos más. Téngase en cuenta que el mero hecho de hablar (por abreviar) de «sociología de la acción colectiva» activa una delimitación muy artificial con respecto a la historiografía de los movimientos sociales y sus innumerables aportaciones, muchas veces basadas en la explotación de fuentes de prensa. En pocos campos como el que concierne al estudio de la acción colectiva popular, la sociología debe tanto a su hermana, la historia social.

EMPIRIA. Revista de Metodología de Ciencias Sociales. N. o 16, julio-diciembre, 2008, pp. 59-84. ISSN: $1139-5737$ 
de problemas y sesgos, sobre todo al depender su realización de la policía- sobre actos de violencia, hostigamiento y discriminación contra minorías y por motivos raciales (Skellington, 1996: 83).

En muchas otras ocasiones, como se apuntaba, la prensa constituye el único «recurso realista» para recopilar información de eventos dispersos en el espacio y en el tiempo, lo que representa una gran ventaja con respecto a «otras fuentes que suelen estar disponibles para más cortos periodos de tiempo» (Barranco y Wisler, 1999: 302). Así, la explotación sistemática de «los periódicos permite el seguimiento de un suceso a lo largo del tiempo, y proporciona la más completa cantidad de eventos para una muestra amplia de unidades temporales y geográficas» (Olzak, 1989: 128).

También resulta frecuente que las ventajas del «análisis de eventos»a través de la prensa se expongan mediante una comparación con las limitaciones que suelen atribuirse a los «estudios de casos». Así, se afirma que, si bien «proporcionan información detallada de los orígenes, de los escenarios y de los participantes en la acción colectiva» (Tilly, 1969: 17), la principal limitación de los «estudios de casos» residiría en la dificultad para determinar si los hallazgos de unos pocos casos estudiados intensivamente, y muchas veces concentrados en el espacio y en el tiempo, son, a su vez, típicos o ejemplares de otros muchos casos en apariencia similares. Estos estudios intensivos, pudiendo servir para la decisiva tarea científica de formular hipótesis alternativas a las establecidas, rara vez proporcionan evidencias sistemáticas para verificar hipótesis o establecer generalizaciones. Justo lo que sí permitiría - al menos eso gustan de afirmar quienes hacen administraciones cuantitativas de los casos registrados en periódicos-el «análisis de eventos». Estrategia que nos aportaría una información homogénea $\mathrm{y}$ en «dimensiones conmensurables» sobre propiedades compartidas por grandes catálogos de casos (Olzak, 1989: 121-122).

Por tanto, otra de las ventajas habitualmente atribuidas a la explotación de periódicos (pero que voy a cuestionar más adelante) sería la de que éstos permitirían determinar las variaciones en la incidencia de un tipo particular de acción colectiva a lo largo de un periodo y a lo largo de un territorio, sobre todo si se explota a la vez prensa nacional y local, y el nivel de infla-representación pe-

${ }^{6}$ En un ya lejano estudio metodológico poco conocido, Tilly (1969) plantea las diferencias entre los «estudios de casos», a los que denomina «análisis clínicos», y el «análisis de eventos», «análisis epidemiológico» en la temprana terminología del autor. Los estudios epidemiológicos «examinan la incidencia de diferentes tipos de violencia en términos de tiempo, emplazamientos y gente implicada [...] Son muestras de unos pocos datos singulares de una gran cantidad de eventos». En cambio, los estudios clínicos «prestan poco interés por hacer los datos comparables. La información es rica, pero el tratamiento cuantitativo es muy difícil» (Tilly, 1969: 17). Los modelos epidemiológicos, por otra parte, relacionan unas pocas variables, identificadas como comunes a toda la gran muestra de casos tratados, con las probabilidades de que ocurra un evento colectivo. Tales «estudios epidemiológicos [mantendrá el citado años después] relacionan unidades — personas, países, ciudades, etc. - implicadas en la violencia, con el conjunto más amplio de unidades que teóricamente podrían haberse visto afectadas [...]. Es una manera de aislar las condiciones que determinan la implicación o no en un conflicto, o el desarrollo o no del mismo» (Tilly et al, 1997: 25). 
riodística permanece constante. Se defiende, por ejemplo, que mediante la prensa, un investigador podría identificar clusters de acción colectiva y «parábolas de movilización popular» (Olzak, 1989: 126). En general, quienes sustentan en la prensa estudios longitudinales sobre conflictos sociales postulan que los cambios en los ratios de conflictos a lo largo del tiempo reflejan la evolución real en la incidencia de la protesta, «más que cambios en las prácticas de selección de los periodistas» (Barranco y Wisler, 1999: 314).

Quizás la mayor de las ventajas atribuidas a la explotación de periódicos, y que a mi entender sí justificaría la utilización de los mismos para estudiar fenómenos de protesta social, consiste en que estas fuentes ofrecen un retrato amplio y rico de las formas, secuencias y resultados de la acción colectiva (Tilly, 1990: 170). La prensa no sólo permitiría determinar con fiabilidad ${ }^{7}$ aspectos obvios como la fecha y localización geográfica de un evento. También revelaría si estamos ante casos monoepisódicos o multiepisódicos ${ }^{8}$. Además, aunque a veces entre periódicos puedan darse las conocidas «guerras de cifras» sobre manifestantes, hay muchas clases de acciones colectivas (protestas antigitanas en la España reciente, por ejemplo) sobre las cuales los distintos periódicos suelen ofrecer pocas discrepancias a la hora de apuntar el número aproximado de participantes ${ }^{9}$. A su vez, la prensa ofrece datos fidedignos, y con pocas variaciones

${ }^{7}$ La determinación de la fiabilidad de los datos de la prensa se sustenta en la triangulación de las fuentes. Mediante la misma podemos comprobar si los datos sobre un suceso registrados en diferentes periódicos son homogéneos, o si, en cambio, varían en función de la fuente manejada. Si en la investigación cuantitativa la cuestión de la fiabilidad de una investigación remite a la estabilidad de los resultados aplicando medidas sucesivas, en el caso de la utilización de la prensa la cuestión de la fiabilidad nos interroga sobre si hay homogeneidad y estabilidad de los datos reportados sobre un evento por parte de distintos periódicos.

${ }^{8}$ En la literatura sobre acción colectiva se habla de casos monoepisódicos cuando una o varias acciones quedan comprendidas en un plazo de veinticuatro horas. Cuando las acciones colectivas se distribuyen fuera de este margen de tiempo se habla de casos multiepisódicos (Olzak, 1989: 121).

${ }^{9}$ Sobre si los periódicos son un buen medio para estimar el número de participantes en una acción existe un largo debate. En su día, autores como Mann (1974) ya sostuvieron que el número de participantes reportados por los distintos periódicos variaba de acuerdo con la orientación política de éstos. Sin embargo, otros trabajos sobre conflictos sociales sí que afirmaban la validez de las estimaciones sobre número de participantes que proporciona la prensa, arguyendo que los periodistas de los distintos medios interaccionan entre sí y tratan de adecuar los datos que ofrecerán en sus crónicas, a fin de hacerlas consonantes (Danzger, 1975). Menos optimistas se muestran otros autores que proponen la necesidad, en el campo periodístico y en el de las autoridades que también ofrecen cifras, de aplicar fórmulas y rutinas para recuentos de multitudes, frente al arbitrio de los periodistas, y de sus muchas veces interesadas organizaciones: «en muchos casos no se ofrece una cifra. $\mathrm{Si}$ se dan cifras redondeadas, suelen ir acompañadas de matices valorativos, tales como cerca de diez mil, más de mil, apenas un centenar» (Adell, 2005: 174). No obstante, convendría advertir que, si bien el número de manifestantes puede considerarse crítico en muchos casos, no en todos los tipos de protestas sociales los distintos medios expresan el mismo interés por sobredimensionar o disminuir el número de participantes. Por ejemplo, en el estudio sobre protestas antigitanas apenas encontramos discrepancias entre el número de participantes publicados la prensa local de los lugares de los conflictos y los señalados por corresponsales de medios nacionales. Se agradecería, no obstante, mayor precisión, aunque siempre suelen expresiones, como la de «alrededor de mil», que permiten hacerse una idea fidedigna de la magnitud de la movilización antigitana.

EMPIRIA. Revista de Metodología de Ciencias Sociales. N. o 16, julio-diciembre, 2008, pp. 59-84. ISSN: $1139-5737$ 
de un periódico a otro, sobre los saldos y el tipo de tácticas empleadas por los actores del conflicto, así como sobre la imbricación o secuencias de una acción colectiva, como aquellas en las que una manifestación concertada deriva en la aplicación de tácticas disruptivas que conllevan ataques a personas o propiedades. Por otro lado, aunque la prensa diste de ser una fuente adecuada para profundizar en los perfiles sociales de los manifestantes, sí suele dar buena cuenta de otros aspectos claves de un conflicto como, por ejemplo, la división de papeles integrados entre participantes que suele producirse en muchas protestas sociales, como aquellas manifestaciones que acaban en «festivales de violencia» a cargo de pequeños grupos que encuentran en manifestaciones y concentraciones multitudinarias el aliento y anonimato necesario para sus iniciativas.

La literatura revisada refleja acuerdo con respecto a la última ventaja apuntada. En su día Danzger (1975: 573), en el curso de un artículo crítico con la validez de datos de conflictos raciales localizados mediante periódicos, se mostraba confiado, en cambio, en la fiabilidad de muchas de las informaciones sobre los conflictos regularmente aportadas por estas fuentes. En este sentido arguyó que quienes critican que los periódicos son fuentes de inexactitudes y distorsiones sistemáticas de los hechos reportados consideran que el proceso de publicación de noticias se inscribe en una cadena unilineal. Para él, sin embargo, muchas noticias sobre conflictos sociales eran confeccionadas en el marco de procesos de interdependencia y colaboración entre los propios periodistas de distintos medios, los cuales compartían muchos de los datos conseguidos sobre los conflictos que reportaban, reduciendo así lagunas e inexactitudes, y mejorando la fiabilidad de la información mediante una especie de ejercicio de triangulación ${ }^{10}$.

En fechas más recientes otras investigadoras han retomado la defensa de la fiabilidad de ciertos datos de la prensa, defendiendo «los periódicos ofrecen in-

${ }^{10}$ A su vez, continúa Danzger (1975: 573), las posibles fuentes de error en el reportaje de un suceso irían neutralizándose a medida que se multiplicara el número de noticias subsiguientes sobre el mismo. El artículo citado, escrito en Estados Unidos, tal vez sea demasiado optimista con respecto a las relaciones de colaboración entre periodistas. No obstante, buena parte de las aproximaciones al campo periodístico se centran en la competencia entre periodistas de distintos medios. Suele, así, despreciarse que la cooperación e intercambio de información entre reporteros de distintos medios resulta la mayoría de las veces tan necesaria como estratégica, a veces más estratégica que la competencia por pertenecer a empresas diferentes. Compartiendo información en el terreno - terreno cada vez más abandonado, cierto es, por la dependencia de «agencias de noticias», en vez de cubrir muchas protestas - los periodistas de medios (sobre el papel competidores) sujetos a similares rutinas de reportaje, no sólo consiguen hacer frente de manera más eficiente a demandas y constricciones organizacionales, como los «cierres de edición». Al compartir la información recabada también consiguen reducir incertidumbres, lagunas a la hora de la composición de las crónicas, y fuentes de errores, los cuales quedarían fácilmente evidenciados debido a la cobertura que realizan sobre el mismo suceso los «colegas» de otros medios, con los que se mantienen inevitables interdependencias. Eso no quiere decir, adelanto, que los periódicos coincidan a la hora de atribuir responsabilidades y reportar las motivaciones de los participantes. Hablamos de datos básicos, obligados y regularmente presentes a la hora de componer el cuadro de noticias, cuyo prisma puede ser muy diferente.

EMPIRIA. Revista de Metodología de Ciencias Sociales. N. ${ }^{\circ}$ 16, julio-diciembre, 2008, pp. 59-84. ISSN: $1139-5737$ 
formación fiable [reliable] en torno a datos como la fecha, localización, los episodios, la duración, y la naturaleza de los conflictos, siendo menos indicados para caracterizaciones sobre los participantes y sus motivaciones» (Ozak et. al, 1994: 206) ${ }^{11}$. En la misa línea Franzosi (1987: 7) subraya que los periódicos suelen ofrecer «información rica, homogénea y significativa» sobre algunas características de los eventos. Proporcionan información «valida y fiable» sobre el tipo de acción de la que se trata. Sobre la localización y fecha del evento. Sobre la identidad general, y en menor medida sobre algunas características generales del perfil social de los participantes (si dominan en las protestas trabajadores, estudiantes, campesinos, miembros de grupos étnicos, religiosos. etc.). A su vez, la prensa proporciona información «valida y fiable» sobre las consecuencias de la acción (si la gente fue atacada, injuriada, arrestada, etc.).

Ahora bien, lejos de mostrarse ingenuamente complacientes con el uso de la prensa, quienes plantean la fiabilidad de esta fuente a la hora de obtener ciertos datos o circunstancias de la acción colectiva - habitualmente reportadas de manera rutinaria en los distintos medios que cubren el evento- también advierten que los periódicos sí suelen desviarse en las interpretaciones que ofrecen sobre las motivaciones de los participantes, variar a la hora de atribuir causas y responsabilidades en los acontecimientos, así como variar en la interpretación general de éstos. En estos aspectos, se admite, la información de la prensa es bastante menos homogénea ${ }^{12}$. Por ejemplo, uno de los citados defensores de la fiabilidad de ciertos datos de la prensa, se toma la precaución de precisar que: «el tipo de sesgos que ocurren en los medios consisten más en el silencio o énfasis en ciertos aspectos de la noticia, que en la inclusión de información falsa [...] La distorsión de las noticias no opera como una alteración de un evento, sino a través de la ocultación o insistencia en determinadas características del mismo que afectan a la imagen de los acontecimientos que acaban haciéndose los receptores de las noticias [...] Pero tenemos más riesgos de información insuficiente que de información falsa» (Franzosi, 1987: 7).

El reconocimiento de cómo los periodistas se enfrentan a la noticia desde «marcos» diferentes, los cuales llevan a enfatizar unos elementos de un suceso en detrimento de otros, enlaza con argumentos centrales de una de las teorías críticas sobre los procesos de producción de las noticias: la «teoría de los encuadres

11 Las autoras, para un estudio sobre protesta racial en los sesenta, contrastaron posibles problemas de fiabilidad del periódico principal de su trabajo: el «New York Times», de los más utilizados por contar con índices que han mantenido un sistema estable de clasificación de noticias. Para ello compararon la información que dio este diario nacional sobre cuatro disturbios raciales, seleccionados al azar, con la cobertura de esos mismos conflictos raciales en cuatro periódicos locales. Su hallazgo fue que no había «discrepancias graves entre la fuente nacional y las fuentes locales» (ibídem, 1994: 206).

12 No obstante, no se puede generalizar. Estudios sobre el tratamiento informativo de disturbios, como los de Gran Bretaña en 1985, han encontrado bastantes convergencias en los marcos interpretativos desde que diferentes periódicos construyeron las noticias sobre los sucesos Van Dijk (1992: VII). 
noticiosos» [«frame of news theory»] trasladada al terreno de la comunicación política por Robert Entman (1993). Según ésta, los medios no sólo establecen la agenda de temas de debate público, sino que también definen una serie de pautas («marcos») con los que pretenden favorecer una determinada interpretación de los hechos sobre los que informan ${ }^{13}$. Quienes han defendido la utilización de la prensa para conseguir datos sobre la protesta social, hemos visto, no niegan que esto ocurra.

\section{La «mala prensa» de los periódicos: respuestas a la literatura crítica sobre la producción de la noticia}

La sucinta exposición de las ventajas de la prensa comprendida en el epígrafe anterior dista (me hago cargo) de ser una exposición que concite consenso. Así, cabría objetar que hasta ahora apenas se ha tenido en cuenta la mucha literatura crítica en torno al papel de los medios de comunicación, en concreto de los periódicos, como agencias con intereses que, además de decidir qué es noticia, deforman y enmascaran la realidad. Los periodistas, se critica habitualmente, no mantienen un espejo frente a los eventos que reportan, pues contribuyen a configurarlos y a dotarlos de sentidos consonantes con las preferencias y valores de los públicos que consumen sus productos; preferencias y valores que los propios periodistas, o sus agencias editoriales, han contribuido a conformar en interacción atenta con los esquemas previos y valores duraderos [enduring values] mantenidos por los masas consumidoras de las noticias.

Así, se plantea frecuentemente que la «selección de noticias es un reflejo de la estructura social fuera de la agencia de noticias» (Gans, 1979: 81). Como en la «fabricación de la noticia» explicarán dos de los más conspicuos representantes de la «escuela de Birminghan», los medios de comunicación son una parte integral de los aparatos ideológicos de reproducción del capitalismo, debido a la actividad que realizan de selección, de interpretación, así como de clasificación [packaging] de la realidad (Cohen y Young, 1973: 17-33) ${ }^{14}$. La selección y presentación de noticias no es azarosa, sino intencionada, pues refleja las visiones, preferencias e intereses de los grupos económicos y burocracias dominantes,

13 El concepto de Goffman aplicado a la comunicación social dio pasó a la teoría del framing. Los marcos se definen como las ideas centrales a partir de las cuales el periodista organiza la noticia. Cuando el periodista enmarca los hechos selecciona y enfatiza algunos aspectos de la noticia que sobresaldrán, de tal modo que promueve una interpretación general del suceso, una interpretación causal, una evaluación moral y una posible solución. Obviamente esta teoría se ha visto completada con la atención a los efectos sociocognitivos que esos procesos de enmarcado [«framing»] ejercen sobre la opinión pública que consume las noticias-mensajes informativos.

14 En un análisis crítico de los medios, por tanto, «habría dos cuestiones que hemos de confrontar cuando tenemos el problema de cómo las noticias son seleccionadas de multitud de eventos que ocurren en el mundo. La primera es, ¿qué es seleccionado? La segunda es la objetividad [namely], ¿con qué exactitud tal selección refleja el mundo real» (Young y Cohen, 1973:17).

EMPIRIA. Revista de Metodología de Ciencias Sociales. N. ${ }^{\circ}$ 16, julio-diciembre, 2008, pp. 59-84. ISSN: 1139-5737 
cuya influencia en los contenidos noticiosos se manifiesta por una doble vía. Por un lado, élites y burocracias son imprescindibles canales rutinarios de información de las que depende el quehacer periodístico ${ }^{15}$. Por otro lado, élites y burocracias políticas y empresariales representan fuentes de subsidio de los costes de los procesos de producción de noticias (Fishman, 1983: 55; Fernández Barba, 1995: 119; Hernández Ramírez, 1997: 17; Ortega y Humanes, 2000: 65) ${ }^{16}$.

Poco cabría oponer a estos argumentos, sobre todo si uno repara en hechos como la inexistencia de noticias sobre «abusos patronales» sentenciados cometidos por grandes empresas que se publicitan a buen precio en grandes periódicos. Sin embargo, al limitarse a las sobredeterminaciones que ejercen «fuerzas externas» sobre la selección de noticias, buena parte de los «análisis críticos» sobre los medios suelen despreciar dos circunstancias que constriñen el margen de manipulación y distorsión de la realidad al alcance de los periodistas y editores, el cual tiende a presentarse como ilimitado en ciertos análisis de «sociología de los medios», cuando no lo es.

En primer lugar, la literatura crítica sobre la selección y producción de noticias minusvalora que el periodismo es y debe ser analizado como un «campo». Si puede hablarse del periodismo como «campo» es porque los actores del mismo, precisamente como forma de mantener el cierto margen de autonomía que constituye y legitima su actividad frente al exterior, han interiorizado y dependen de lógicas de funcionamiento específicas que dan lugar a categorías cognitivas, reglamentos y rutinas que, una vez objetivadas, ejercen un efecto constrictivo sobre todos los actores, limitando las posibilidades de actuar (a la hora de reportar una noticia, por ejemplo) al margen de las «reglas sociales» del «campo». Al constituirse la acción de informar inevitablemente bajo las reglas del «campo», cuyos principios estructurantes son reforzados en cada acto de sujeción al mismo, los periodistas y las organizaciones a las que ofrecen sus servicios entran, en

15 Ortega y Humanes (2000: 65) han señalado las consecuencias de esta dependencia. Apuntan que, si exceptuamos los acontecimientos imprevisibles cuya aparición produce rupturas en la cotidianeidad, la atención del periodista está limitada a quienes tienen el poder para 'pasarles' información. En vez de la sociedad y sus múltiples actores, aparece un reducido núcleo institucional (a veces dotado con «gabinetes de comunicación») capaz de saturar la agenda de los periodistas, de proporcionar representaciones de lo social asimilables por la maquinaria de la información, así como de imponer una visión sesgada, esto es, construida desde sólo unos pocos poderosos focos de atención, los cuales dominan y reducen la tarea del periodista.

16 Versiones aún más críticas plantearan que los medios de comunicación, concebidos como agencias reproductoras de los intereses de las elites a las que se subordinan, no reflejan el mundo de ahí fuera, sino las prácticas y los intereses de aquellos grupos que tienen el poder de determinar la experiencia de otros (Molotch y Lester, 1974: 111; Chomsky, 1992). Para garantizar esta situación es imprescindible el aprendizaje de la política empresarial por parte de los profesionales. Como mostró el clásico estudio de Breed (1955), la clave de la adecuación de los periodistas a los intereses y valores corporativos, en detrimento de la independencia, residiría en la socialización y control al que se ven sometidos los periodistas en las redacciones, sobre todo la ejercida por los editores hacia los nuevos profesionales, los cuales terminarán por interiorizar la línea editorial del medio mediante un proceso de osmosis incentivada por factores como las aspiraciones de promoción.

EMPIRIA. Revista de Metodología de Ciencias Sociales. N. ${ }^{\circ}$ 16, julio-diciembre, 2008, pp. 59-84. ISSN: 1139-5737 
suma, en una situación de interdependencia que lleva, por ejemplo, a mirarse tanto entre sí, como al lugar de la noticia. Puede decirse, entonces, que el qué y el cómo de la información que se elija por parte de un periodista no está sólo subordinado a los empresarios o élites periodísticas, de los que también se depende, sino a las relaciones de interdependencia que se mantienen con los colegas y medios de la competencia, los cuales influyen con sus otros servicios-noticia, en el valor social del servicio-noticia que ofrezca nuestro atrapado periodista.

Por otro lado, dada la complejidad del discurso informativo, una parte importante de los esfuerzos de los profesionales ha de centrarse en el desarrollo y sujeción a pautas y controles eficaces y coherentes en torno a la producción de noticias. De esta manera, otro elemento constitutivo de los campos (y que se identifica también en el periodismo) es la vigencia de estas tecnologías institucionales que contribuyen, además de a limitar las injerencias desde otros sectores, a estandarizar la acción informativa, así como a introducir unos mínimos de previsión sobre el tratamiento de las mismas noticias que realizarán los periodistas de otros medios.

Y otro motivo por el que (a mi entender) el periodismo constituye un «campo» radica en un hecho advertido por Ortega y Humanes (2000: 61): los procesos de acceso a la profesión son competencia de los propios profesionales, no del grupo empresarial. Al controlar los periodistas su reproducción profesional, controlan no pocas de las reglas propias del oficio y conservan muchas de sus posibilidades de autorregulación. Además, la socialización informal posterior en la organización también es dominada por el grupo profesional, si bien ello no excluye el que se dé a su vez una adaptación condicionada de los periodistas a los valores de la organización, a la línea editorial del diario, etc. (Breed, 1955).

De esta manera, a la hora de fabricar y reportar noticias sobre protestas sociales el margen de acción (cabría decir el margen de manipulación o de ofrecimiento de información falsa) de los actores del campo periodístico se ve constreñido por la interdependencia entre diarios diferentes obligados a competir por mantener ante sus volátiles públicos el valor la «credibilidad» — «carta de nobleza» estructurante de valores sociales en el campo periodístico, que pesa sobre los actores del mismo, y sobre la cual descansa buena parte enjuiciamiento de los periodistas y de sus empresas por parte de otras fuerzas externas-. Dicha competencia e interdependencia dentro del campo exige el sometimiento común de los integrantes a estándares compartidos de objetividad y relevancia a la hora de decidir qué es noticia. Estándares transformados en habitus que los periodistas (a veces lo olvidamos, reduciéndolos a «muñecos estereotipados») interiorizan durante su socializaciones profesionales formales e informales. Así, en el momento de decidir qué sucesos finalmente se publican y a la hora de decidir cómo los mismos se narran y reportan, los «jefes de información» o editores de un diario, en lugar de poder manipular y filtrar a su antojo la agenda informativa - como sostendría la vieja «teoría del gatekeeper» de la información-, deben ajustarse a la selección y tratamiento a la vez emprendido por los otros medios competidores, a cuyas noticias y agendas informativas se atiende 
celosamente en cualquier periódico a fin, fundamentalmente, de no quedar en evidencia ante audiencias que tienen a su alcance otras fuentes para informarse ${ }^{17}$.

Lo apunta Fernández Barba (1995: 116-119) en su análisis de la conformación de habitus profesionales en el campo periodístico: la posición y legitimidad de una «organización noticiosa» en el mercado está directamente vinculada a su habilidad para mantener la «integridad de su operación noticiosa ${ }^{18}$. Resultará difícil asegurar una posición competitiva en el mercado si en las noticias predominan aspectos idiosincráticos, o se reportan de manera extraordinariamente política e ideológica. La competencia entre medios exige, en consecuencia, de una sujeción por parte de todos los actores en competencia del campo periodístico a estándares comunes que mantengan uso mínimos de objetividad y fiabilidad de las «operaciones noticiosas». Algo que se consigue, continúa Fernández Barba, mediante la interiorización por parte de los periodistas de una serie de rutinas compartidas de reportaje ${ }^{19}$.

El seguimiento de estas rutinas deviene fundamental para que la cobertura y tratamiento de un suceso se considere adecuados por parte de los editores, si bien dada la carga de trabajo que acumulan éstos no suelen estar en condiciones de supervisar todo el trabajo de los reporteros (Ortega y Humanes, 2000: 111). Tuchman (1983), una autora que no suele faltar entre las citas de la literatura crítica sobre el periodismo, detallaba alguna de esas rutinas en su clásico estudio sobre las «estrategias rituales» que siguen los periodistas para no obligarse a disentir y conseguir la aceptación de sus noticias por los editores. En el caso concreto de noticias sobre «hechos» que implicaban alguna disputa o conflicto social, lo que nos acerca a nuestro asunto de la cobertura periodística de las movilizaciones sociales, halló que se seguían normas compartidas como: i) presentar ambos lados de la disputa, dando la voz a las partes en desacuerdo, ii) incluir frases que corroboren los reclamos de los que luchan por establecer la verdad, iii) utilizar citas para mostrar que la fuente está relatando el hecho, situación o problema, y iv) organizar historias o relatos para presentar de manera clara y coherente el asunto. Estas rutinas seguidas por los periodistas contribuirían a au-

${ }^{17}$ Lo apuntado sobre la lógica del campo periodístico no supone afirmar ingenuamente la existencia de un verdadero pluralismo informativo en nuestras sociedades. No pierdo de vista que el «orden mediático» actual, como en su día previera Marx, supone la intensificación de la concentración de la propiedad de los periódicos en un núcleo reducido de grandes y poderosas corporaciones que estandarizan lo noticiable y el contenido de lo finalmente comunicado bajo conceptos unidimensionales, como podría estar ocurriendo hoy con la definición periodística dominante sobre lo que es/no es «terrorismo».

${ }_{18}$ Bourdieu no estaría lejos de esta idea. Tras advertir que el campo periodístico presentaba la particularidad de depender mucho más de «fuerzas externas» que cualquier otro campo de producción cultural, matizaba que el periodismo «está sometido a la sanción del mercado, del plebiscito, incluso tal vez más que el campo político» (Bourdieu, 1997: 77).

${ }^{19}$ Esa sujeción a reglas y esas auto-regulaciones a la hora de la producción de la noticia no tienen, por lo demás, porqué enfrentarse a los intereses de las empresas periodísticas. «Son los ajustes entre profesionales los que a la larga producen resultados más positivos para el balance empresarial» (Ortega y Humanes, 2000: 61). 
mentar la mejorar de los datos sobre un suceso reportados en distintos medios (Tuchman, 1983: 119) ${ }^{20}$.

Frente a lo que habitualmente presuponen los muchos críticos de la manipulación informativa, estudios como el citado muestran que la producción de noticias se presenta como un trabajo altamente codificado. Esta alta codificación del quehacer periodístico - la restricción por parte de los periodistas a rutinas aprendidas de reportaje, o la sujeción a formas narrativas de publicación estandarizadas y predecibles, por ejemplo- constituye un medio del que se valen los periodistas para mantener cierta autonomía, así como para reducir riesgos dentro de un campo con actores expuestos permanentemente a perder legitimidad ante un tratamiento noticioso que puede ser desacreditado por las revelaciones contenidas en las noticias de los otros medios competidores.

En segundo lugar, los «análisis críticos» sobre los medios, al centrarse exclusivamente en las sobredeterminaciones externas a las que se verían sometido los actores del campo periodístico, rara vez tienen en cuenta los condicionantes organizacionales que afectan a la práctica periodística y a la producción de noticias. Sin embargo, como explica Hernández Ramírez (1997), la posibilidad de que un hecho se convierta en noticia no sólo depende, digamos, de la heteronomía de los periodistas y sus editores con respecto a la ideología editorial, a su vez subordinada a imperativos económicos y políticos. En muchas ocasiones, el que un suceso termine o no en noticia depende, en lugar de los intereses y subordinaciones editoriales, de la estructura y dinámica interna del medio y, sobre todo, de las rutinas profesionales de los periodistas ${ }^{21}$. Al tanto enfatizar en la manipulación de la agenda informativa, se pierde de vista lo mucho que en la selección de noticias influyen en las circunstancias y posibilidades de cobertura de los medios, esto es, cuestiones técnicas como la densidad de agencias de prensa

${ }^{20}$ Existiría, en consecuencia, una «cultura profesional» del periodista relacionada los criterios de relevancia que aplican los periodistas a la hora de seleccionar los acontecimientos de un modo que satisfagan las necesidades y pautas de la organización, lo que exigiría atender a los «marcos» de producción de la noticia. Sin embargo, otra parte fundamental de dicha cultura profesional remite a los formatos y tratamientos que se da a las noticias. Gran parte de la cultura profesional del periodismo consiste en la capacidad de tipificar los sucesos con las técnicas apropiadas (Tuchman, 1983, cit. Ortega y Humanes, 2000: 115).

${ }^{21}$ Periodistas, dicho sea de paso, cuyo grado de autonomía producto de socializaciones profesionales en las que éstos incorporan hábitos y reglas estandarizadas de reportaje - a fin de cuenta «métodos», si tomamos en cuenta la acepción débil de la expresión-, suele minusvalorarse por parte de muchos sociólogos, esto es, por parte de otros profesionales que, además de mantener una posición similar como «clases de servicio» en el espacio social, ocupan también una posición «crítica» en la definición social pertinente de la realidad. Aunque no sea este el momento, algún día habría que detenerse, por ejemplo, en el activo papel que ha jugado «la sociología del final de las clases» en la desrepresentación de fenómenos cuyos componentes y contornos de clase son sistemáticamente soslayados. En esa desrepresentación, trasladada al tratamiento informativo de sucesos donde la clase social de los actores de las noticias está ausente, el periodismo (me atrevo a afirmar) ha jugado un papel pasivo, al menos en comparación al activo papel desempeñado por un tipo de sociología dominante que, dejando de ofrecer una representación de las clases, no podía dejar de influir en su continuamente aireada desaparición.

EMPIRIA. Revista de Metodología de Ciencias Sociales. N. ${ }^{\circ}$ 16, julio-diciembre, 2008, pp. 59-84. ISSN: $1139-5737$ 
en el lugar de la noticia, o la distribución del tiempo disponible para cubrir noticias sometidas, por otro lado, al imperativo de los «cierres de edición». Así, algunos estudios muestran cómo la probabilidad de cobertura de las «demostraciones públicas» está desigualmente distribuida, disminuyendo las oportunidades de que tales casos integren la agenda informativa a medida que crece la distancia entre el lugar del acontecimiento y el lugar de edición del periódico. Además, debido a la constante carencia de tiempo para cubrir eventos muchas veces coetáneos, los periodistas prefieren centrarse más en los acontecimientos previstos y continuados, muchas veces planificados por gabinetes de comunicación, en detrimento de los únicos, inesperados y nuevos (Barranco y Wisler, 1999: 307).

Por otra parte, la cobertura por un periódico de un suceso también dependerá de si existen imágenes televisivas sobre el acontecimiento, multiplicándose en tal caso las posibilidades de publicación (Gans, 1979: 159)22. A su vez, en las probabilidades de publicación influirá el que éste revista a priori la condición de dramático e impactante, atractivo para el periodismo (Molotch y Lester, 1974). A su vez, las posibilidades de publicación de un evento variarán en función de cuál sea la instancia a la que se dirija de la acción (McCarthy et. al., 1996), así como el tipo de convocatoria que se realice para los periodistas. De hecho, como mostraron Kielbowicz y Scherer (1986) analizando el «rol de la prensa en la dinámica de los movimientos sociales», con frecuencia la mayor posibilidad de publicación de un acto estará ligada a la capacidad de los líderes y organizadores de la acción colectiva para concertar la presencia de los periodistas, ofreciéndoles citas atractivas que incluyan la manipulación de recursos simbólicos condensadores del sentido de la acción, así como facilidades de cobertura rápida. Esto es lo que ocurre con los llamados «eventos planeados» por y para ser cubiertos por los medios de comunicación.

Habría que tener en cuenta, por tanto, que la selección de noticias se ve afectada por al menos dos procesos, ambos cruciales. «Uno determinado por la disponibilidad y accesibilidad [availability] a las noticias, el cual relaciona a los periodistas con las fuentes. Y otro determinado por la conveniencia [suitability] de las noticias, el cual relaciona a los periodistas con la audiencia» (Gans, 1979: 81). El primero de esos procesos nos remite a la estructura interna de la comunicación, a las circunstancias y constricciones de cobertura bajo la que operan los

22 En su gran estudio teórico sobre los movimientos sociales señalaba el fuerte efecto de dominación que ejerce la televisión sobre el resto de las agencias y actores del campo periodístico. Allí donde aparece la televisión, se produce una «obligada» presencia para los informadores de otros medios, adecuando además sus crónicas a la poderosa pauta que marque la televisión con lo que diga y muestre. A veces es más importante para el periodista ajustar su crónica al guión y contenido de la noticia televisiva que asomarse a ver qué se ve por la ventana, como comprobamos durante un trabajo de campo en un escenario de ataques a viviendas gitanas: «Me los encontré en el hotel haciendo las crónicas, y viendo a ver qué decía el telediario. Ya habían pasado varios días, y la cosa estaba caliente. Y yo ya no pude aguantarme más: ijoder, hablar con la gente! Qué venís, nada más que a cobrar las dietas» [J.L.Q., maestro de M.R. y colaborador en medios provinciales, cit. Río Ruiz, 2003: 150]

EMPIRIA. Revista de Metodología de Ciencias Sociales. N. ${ }^{\circ}$ 16, julio-diciembre, 2008, pp. 59-84. ISSN: 1139-5737 
actores del campo periodístico: a sus fuentes, al número de noticias que puedan cubrirse en un día, a las competencias y subordinaciones de la prensa escrita respecto a otros medios como la televisión, a la localización de las agencias de prensa con respecto al lugar de la noticia. El segundo proceso que influye en la selección de noticias, en cambio, nos remite a la estructura social en la que se inscribe la «manufacturación de noticias», esto es, a los intereses sociales que influyen en qué y cómo se publica.

Por otro lado, frente a las posturas que plantean el descarte de la prensa arguyendo los múltiples sesgos y distorsiones que acompañan a esta fuente, cabe desarrollar una cuestión ya apuntada: ¿Acaso no son todas las fuentes secundarias fuente de sesgos y de problemas de fiabilidad? ¿Es que hay fuentes que mantienen un espejo frente a los fenómenos que registran y describen? ¿Acaso hay fuentes que garantizan que los «hechos» recogidos y descritos no han pasado por «cedazos y molinillos» similares a los que utilizan los periodistas y sus editores?

En cualquier proceso de investigación documental nos exponemos a problemas de fiabilidad de la información similares a los derivados del recurso a los periódicos, de ahí la siempre recomendada diversificación y triangulación de fuentes (Rucht y Neidhart, 1998). Ante las «movilizaciones racistas», por seguir con un ejemplo en el que nos venimos apoyando, los periodistas ofrecen datos tan enfrentados con la investigación social como los de los ediles que en un pleno aprueban un manifiesto sobre un conflicto antigitano en un pueblo, mientras miles de votantes esperan frente al ayuntamiento, y al borde del estallido, una resolución inaplazable del poder local que se juega, con su posición publicada ante el conflicto, buena parte de su nota final medida en votos. Al igual que sucede con los «fabricantes de noticias», los otros actores y agencias que producen documentos sobre conflictos sociales, aunque sean instituciones oficiales, se deben a las expectativas de las grandes o más pequeñas clientelas que reciben y evalúan las posturas y decisiones de las que dejan constancia escrita. Ninguno de los productores de documentos - ni los que los hacen con fines publicitarios, ni los que los hacen con fines de consumo interno, ni los que los hacen porque así lo exige la institución pública en la que trabajan - mantienen un espejo frente a los «hechos» que describen y publican. Todas las agencias que producen documentos limitan y seleccionan lo descrito, al tiempo que atribuyen motivaciones y cualidades a un fenómeno o suceso en función de sus intereses como organizaciones, así como en función del marco de tradiciones, oportunidades y constricciones políticas y organizacionales en el que estas agencias producen los documentos (Combessie, 2001: 23-25). Todas las fuentes representan «instrumentos de construcción de la realidad que fingen reproducir. Olvidamos a menudo que una parte importante de los historiadores es el producto de un trabajo semejante de construcción» (Bourdieu, 2003: 71). Por ello, la vigilancia epistemológica debe desplegarse sobre cualquier tipo de fuente, pues «ninguna de ellas carece de errores. En ausencia de sistemática y comparativa validación, no hay ninguna razón a priori para creer que los datos recogidos de los pe- 
riódicos sean menos fiables que otros habitualmente usados» (Franzosi, 1987:7) ${ }^{23}$.

Ahora bien, la invitación a relativizar o poner continuamente en cuestión todas las fuentes secundarias de las que se extraen datos sobre la protesta, en lugar de únicamente los periódicos, no implica en modo alguno presuponer que periodismo e investigación social se sitúen al mismo nivel, esto es, que compartan las mismas pautas y sigan las mismas lógicas a la hora de su representación de la realidad social. Lo que separa decisivamente el quehacer periodístico del trabajo del científico social, además del tiempo, son operaciones ausentes en el periodismo, como la identificación de las condiciones de producción de la fuente de las que se extraen los datos, el control y selección de los casos y de las variables a observar, así como la puesta en marcha de procedimientos de verificación de los datos que van más allá de la mera diversificación de fuentes ${ }^{24}$.

\section{PROBLEMAS Y LIMITACIONES DE LA PRENSA COMO FUENTE DE DATOS SOBRE LA ACCIÓN COLECTIVA}

Los mayores problemas de los periódicos comienzan cuando se abusa de lo que los mismos pueden ofrecernos, esto es, cuando se utilizan los datos recabados en estas fuentes para ejercicios demostrativos que, aún pudiendo sustentarse en hipótesis plausibles y potentes teóricamente, no revisten suficientes garantías de validez, debido a la «naturaleza» de la fuente manejada para «demostrarlas». Estos problemas de validez de los datos de la prensa resultan es-

${ }^{23}$ A modo de ejemplo: reparemos por un momento en los sesgos derivados de la frecuente utilización, a la hora de analizar protestas sociales, de los registros policiales sobre detenidos en desórdenes públicos. Durante décadas muchos sociólogos de la protesta social manejaron datos que supuestamente avalaban la teoría del «riff-raff» — traducible como la vieja «teoría de la chusma» que presupone el perfil y procedencia marginal y desafiliado de los grupos más proclives a participar en desórdenes- . La fuente que proporcionaba los datos que avalarían esa teoría eran registros policiales, tal vez preferidos por su objetividad frente a los relatos impresionistas (y tampoco adecuados) sobre los perfiles de los participantes que proporcionaban los periódicos. Sin embargo, estudiado está que la policía reúne una larga tradición de aplicación de sistemáticos procedimientos de filtro y selección social a la hora de ejercer las detenciones en un disturbio (Javaloy, et. al., 2001: 175-177). Este ejemplo, por otro lado, ilustra hasta qué punto la naturaleza de la fuente manejada por quien investiga influye en los resultados científicos, siempre leídos al abrigo de teorías cuyos efectos sociales van más allá de meras acumulaciones de saber en el campo, dada la «reflexividad» de los actos de conocimiento sociológico. De hecho, la «teoría de la chusma» sigue formando parte de los «manuales de control de masas» de las policías españolas. No son los periodistas los únicos profesionales con poder para crear imágenes distorsionadas de la realidad, pero con efectos sociales a la hora de orientar la acción de las audiencias.

${ }^{24}$ En este punto mi planteamiento diverge de quienes subrayan que «el periodismo, como la sociología, es una disciplina empírica, de forma que las noticias no sólo consistirían en los hallazgos de investigación empírica de los periodistas, sino también en los conceptos y métodos que entran en esa investigación, en los presupuestos que subyacen a tales conceptos y métodos que intervienen en esa investigación, y en un conjunto más amplio de presupuestos que podrían ser comprobados empíricamente si los periodistas tuvieran tiempo» (Gans, 1979: 39).

EMPIRIA. Revista de Metodología de Ciencias Sociales. N. o 16, julio-diciembre, 2008, pp. 59-84. ISSN: $1139-5737$ 
pecialmente graves cuando, mediante la administración cuantitativa de grandes corpus de casos extraídos de periódicos, tratamos de establecer el incremento y declive en la incidencia social de ciertas formas de acción colectiva a lo largo de un período.

En el apéndice metodológico que acompaña a su libro sobre «el siglo rebelde» la familia Tilly apunta la idoneidad de los diarios para embarcarse en ese tipo de «aventuras sociométricas». Sostienen que: «el buceo en la prensa nos proporciona una muestra más exhaustiva y uniforme de sucesos que cualquier otra fuente alternativa disponible» (Tilly et. al., 1997: 359). En otro pasaje al comienzo del libro mantendrán también que: «una serie continua de un periódico nacional es una fuente más fiable que cualquier combinación de obras históricas normales, y superior a cualquier otra fuente continuada que pudiera resultar utilizable en la práctica» (ibídem, 1997: 27).

Aunque no entremos a cuestionar estas (tal vez algo extremas) aseveraciones a cargo de autores con una dilatada y reconocida experiencia en la explotación de variadas fuentes sobre conflictos sociales, sí es necesario detenerse en una cuestión crítica, sin embargo no desvelada por Charles Tilly y colaboradores. La de si garantizan esos grandes corpus de eventos que proporciona la revisión sistemática y prolongada de la prensa la validez de los resultados.

La experiencia y estudios sobre el asunto muestran que si se recurre a una administración cuantitativa-distributiva de los datos de periódicos caben metodológicas dudas, como la de en qué medida esos hallazgos son el resultado de procesos de la vida real, y en qué medida, por el contrario, son artefactos de las pautas de publicación de noticias de las agencias de prensa. Expresado de otra manera. Al trabajar con periódicos podemos estar seguros de que algún tipo de conflicto acaeció. Pero, ¿hasta cómo podemos estar seguros de que no estamos cuantificando alteraciones en la agenda informativa, en vez de variaciones en la incidencia social real de un tipo de sucesos a lo largo del tiempo? Por ejemplo, ¿podría un incremento del veinte por ciento en la frecuencia de reportaje de protestas antigitanas representar similares tendencias reales? ¿Acaso no nos arriesgamos a que ese, aparentemente contundente, incremento en los ratios de protestas se deba a factores como la implantación por un periódico de secciones regionales en las que encuentran cabida más sucesos etnicistas, $\mathrm{o}$ al desenlace de ciclos de atención mediática en torno a este tipo de acontecimientos? Sostenemos, de acuerdo con Franzosi, que a la hora de utilizar periódicos los errores de validez son mayores que los de fiabilidad. Y ello porque «las pautas temporales y espaciales de reportaje de eventos en los periódicos no se corresponden con pautas de la vida real» (Franzosi, 1987: 7).

El problema es especialmente grave si se utilizan sólo periódicos de ámbito nacional, como han mostrado recientemente Myers y Caniglia (2004). La estrategia de ambos consistió en comparar el catálogo de disturbios raciales registrados (entre 1968 y 1969) en decenas de periódicos locales de todo Estados Unidos, con el conjunto de casos reportados en los dos grandes periódicos nacionales como el New York Times y el Washingthon Post, precisamente los más 
usados para localizar y trazar variaciones en los ratios de disturbios raciales. Resultado: hallaron que menos de la mitad de los conflictos que sí habían localizado reportados en los diarios locales fueron, a su vez, publicados también por los dos grandes diarios nacionales citados.

Estimada la infra-representación, dieron un paso más con el objetivo de identificar cómo afectaba la explotación únicamente de periódicos nacionales - a la que se habían limitado la mayoría de los analistas de los disturbios-a los resultados que sostendrían esas investigaciones. Para ello analizaron, primero, todos los casos recopilados (en diarios nacionales y provinciales). Luego replicaron el análisis, pero ahora incluyendo sólo el corpus de casos registrados en prensa nacional. La replicación arrojó sustanciales diferencias, desvelando sesgos introducidos por las fuentes utilizadas para los hallazgos establecidos sobre disturbios raciales, como el que establecía que existía una relación positiva entre tamaño de las minoría en un lugar y probabilidad de disturbios. Hallazgo que ya había cuestionado Spilerman (1970) y que no era sino un reflejo de la tendenciapreferencia (por parte de los diarios nacionales) a publicar noticias de conflictos acaecidos especialmente en grandes ciudades, precisamente donde la concentración y tamaño de la minoría tendía a ser mayor.

A su vez, tras plantearse los factores que determinaban la inclusión o exclusión de un conflicto de la agenda de los diarios nacionales, quienes firman este completo artículo mostraron que la publicación de un disturbio en tales medios no dependía de diferencias cualitativas entre los casos que entraban y los que quedaban fuera de la edición, ni del atractivo periodístico entre los primeros y los segundos. La publicación de un conflicto dependía de otras circunstancias. Entre ellas: la distancia entre el lugar del conflicto y los lugares donde se ubicaban las oficinas de los diarios nacionales, el tamaño de la población donde ocurría el disturbio, el estatus o significación política de los grupos que sufrían daños, o el día de la semana en que acaecía el conflicto.

¿Y si junto a nuestros diarios nacionales explotamos periódicos locales, como frecuentemente se aconseja? ${ }^{25}$ De esta manera, el catálogo de casos registrados aumentaría notablemente. Ahora bien, ni tan siquiera explotando también diarios locales, a fin de reducir los sesgos de cobertura que se producen por los rotativos nacionales, está garantizada la validez de la «aventura sociométrica» emprendida. Y ello porque «existe un básico isomorfismo en los sesgos a través de diferentes periódicos [...] Prensa local y nacional pueden compartir el mismo conjunto de sesgos relacionados con la lógica de los mass media. Y esos sesgos sólo pueden corregirse mediante la obtención de datos provenientes de fuentes no periodísticas» (Barranco y Wisler, 1999: 304). Así, un trabajo consistente en

25 Por lo demás, una estrategia con elevados costes, al menos antes de existiera y se difundiera la prensa electrónica. Recurso que abre oportunidades para buscar en decenas de periódicos desde el sillón —algo positivo — . Instrumento que — algo no tan positivo— también está potenciando que los periodistas se queden en su sillón, consiguiendo los datos que necesitan para las noticias a través de internet, y frecuentemente a través de otros diarios en la red; reduciendo con este proceder en alza todavía más su tipo de fuentes. 
la búsqueda en periódicos locales de un catálogo de 382 eventos que «implicaban conflicto social», y que fueron localizados con anterioridad en registros policiales, halló que «los periódicos locales cubrieron el 32\% de los [382] eventos [registrados por la policía]» (Oliver y Myers, 1999: 38) ${ }^{26}$. Otro reciente artículo con datos de 43 protestas étnicas en Canadá, a las cuales se intentó localizar en siete distintos periódicos, mostró que sólo algunas acciones del repertorio fueron cubiertas por los siete diarios a la vez, si bien los ratios de cobertura mejoraban a medida que pasaba el tiempo (Wilkes y Ricard, 2007).

Respecto al tipo de problemas enunciados, se ha argüido que si se enmarca la investigación en un período sociohistórico en el que el nivel de infra-representación periodística de un tipo de conflicto social permanece constante - a lo largo del periodo analizado - el problema puede no resultar tan grave (Olzak, 1989). La prensa funcionaría como un «termómetro» que medirá la temperatura incorrectamente, pero que al hacerlo de manera constante permitiría observar los cambios de temperatura (Barranco y Wisler, 1999: 302). El problema es que en la práctica resulta difícil que se produzca tal constancia en la infra-representación periodística de cierto tipo de conflictos sociales (protestas étnicas, huelgas, etc.). Incluso si no se producen alteraciones en la línea de interés editorial de un periódico a lo largo del tiempo - algo poco probable cuando hablamos de décadas de vida de un diario y de una sociedad- lo más frecuente es que los casos registrados en la prensa se vean expuestos a «ciclos de atención mediática» que no necesariamente se corresponden con «ciclos de movilización» real. Como plantean recientes trabajos (McCarthy et al, 1996: 480-482; Olivers y Myers, 1999: 39), los medios de comunicación juegan un rol central en la formación de «ciclos de interés» y «atención mediática» en el curso de los cuales aumentan las probabilidades de que una clase especial de sucesos (protestas antigitanas, por ejemplo) sean cubiertos en ciertos momentos, tras etapas de invisibilidad, o de menor y menos constante atención mediática. Estos cambios en las prioridades de la agenda informativa, por otro lado, pueden producirse sin que necesariamente se den también variaciones en el contexto sociopolítico en el que se inscribe un tipo de sucesos ${ }^{27}$.

La prensa tampoco resulta un buen instrumento para determinar la distinta

${ }^{26}$ Bastante antes otros trabajos ya habían mostrado que dentro de un serial de conflictos como el conformado por los episodios de tensión racial acaecidos en Estados Unidos durante los sesenta - no todos los casos integrantes del mismo presentaban la misma probabilidad de convertirse en noticia. Así, Snyder y Kelly (1977) compararon para el período comprendido entre 1965 a 1969, y para 43 localidades de Estados Unidos, la cobertura de episodios de tensión racial en la prensa nacional y la prensa local. Concluyeron que la intensidad del conflicto - determinada por el hecho de que se produjeran o no ataques colectivos a miembros del otro grupo, así como por el número de participantes en las acciones - afectaba positivamente a la probabilidad de que un conflicto terminara reportándose en periódicos nacionales como el «New York Times», del cual habían dependido los investigadores debido, sobre todo, a que contaba con índices que facilitaban la localización de casos.

${ }^{27}$ Un buen ejemplo, una vez más, nos lo proporciona lo sucedido con las movilizaciones antigitanas en 1991, precisamente el año del posfranquismo en el que más casos de conflicto con gi-

EMPIRIA. Revista de Metodología de Ciencias Sociales. N. ${ }^{\circ}$ 16, julio-diciembre, 2008, pp. 59-84. ISSN: $1139-5737$ 
incidencia y distribución de formas particulares de protesta social a lo largo y ancho de la geografía de un Estado. Por un lado, en el caso de diarios de ámbito nacional, nos encontramos con que la implantación geográfica de las oficinas del periódico afecta a las probabilidades de inclusión de suceso, sesgando así cualquier mapa de conflictos sociales confeccionad vía casos localizados en la prensa. Por ejemplo, la sucesiva creación en diferentes momentos de secciones regionales en periódicos estatales - pensemos en el caso de El País antes de que hubiera secciones regionales en todas las comunidades- multiplica las posibilidades de que en aquellas zonas en las cuales el periódico empieza a contar con páginas regionales se noticien un mayor número de casos (de movilizaciones antigitanas, por ejemplo). Acontecimientos que, antes de la creación de esas secciones, no tenían tantas posibilidades de convertirse en noticia publicada. Ni que decir tiene que, si no controlamos este sesgo, nos exponemos a intentar explicar la mayor incidencia de un fenómeno en ciertas regiones o áreas en función de circunstancias o características sociales específicas de las mismas cuando, en realidad, a lo que nos enfrentamos es a una distorsión propiciada por la fuente que manejamos para localizar casos. Así, como ya apunté, la revelación de los sesgos geográficos que presentaban los periódicos norteamericanos más utilizados (en la década de los sesenta) para localizar disturbios raciales - grandes diarios nacionales que, sin embargo no publicaban con la misma probabilidad los disturbios acaecidos en localidades pequeñas, alejadas de las sedes del periódico- ha contribuido a refutar muchas de las explicaciones que se manejaron sobre los escenarios sociales más probables de estos conflictos (Myers, 1997).

En su día, diferentes estudios mostraron estos riesgos de determinar los espacios sociales más probables de los conflictos acudiendo a fuentes de prensa. Danzger (1975) halló que la desigual distribución en el territorio de la «agencias de prensa» representa un factor estructural de infra-representación periodística de una parte de los conflictos ocurridos. En concreto, de aquellos casos acaecidos en localidades pequeñas y alejadas de aquellas otras localidades de mayor tamaño en las que se ubican casi siempre las agencias de prensa. Así, las posibilidades de que los periódicos terminen noticiando un suceso disminuye a medida que aumenta la distancia entre el lugar donde éste ocurre y el enclave de la agencia. También Tilly (1969: 28) advertía que el principal sesgo de la prensa remitía a la sobre-representación de eventos en las grandes ciudades, en detrimento de las pequeñas comunidades. Estudios más recientes sobre pautas de cobertura periodística de «demostraciones públicas» en Estados Unidos han mostrado que, incluso en una misma gran ciudad, las probabilidades de que el evento sea cubierto y noticiado está influida positivamente por el hecho de que el mismo

tanos se registran en periódicos nacionales. Pero, en 1991, no asistimos a una parábola de movilización popular antigitana, sino a un ciclo de atención mediática que, precisamente, se configura a partir del impacto mediático que tienen casos (televisados) como los de Mancha Real o Villaverde, ocurridos entre la primavera y otoño de ese año 1991, y los cuales suponen hitos históricos en la transformación del «racismo que viene» en problema social y periodístico de primer orden. 
acontezca en «localizaciones centrales» de la misma (Oliver y Myers, 1999: 77).

Por otro lado, la aquí desaconsejada explotación de la prensa con afán de ilustrar las variaciones geográficas en la incidencia de un fenómeno, tropieza con otro elemento de distorsión que afecta a la validez de los resultados: la «lógica del antecedente cercano» que domina buena parte de la actividad de selección y cobertura periodística. Dado que, a la hora de la selección de noticias, los periodistas tienen tendencia a cubrir y reportar sucesos localizados en zonas donde previamente ya se han producido casos similares previamente reportados (Champagne, 1999), las probabilidades de que sea noticiado un evento - protestas antigitanas, por ejemplo - serán mayores si el nuevo acontecimiento se produce en lugar cercano, o en el mismo lugar, en el cual ya se han producido esos antecedentes parecidos en su día reportados. Todo ello deriva en la sobre-representación periodística de ciertos sucesos en ciertas zonas. Y ello cuando, en la práctica, casos similares en otras zonas no son cubiertos, al menos con la misma probabilidad.

\section{CONCLUSIONES}

La prensa es una fuente central de datos para la sociología de la acción colectiva. A la hora de explotar periódicos para estudiar protestas sociales, los problemas de fiabilidad, como los que engendrarían las distorsiones y variaciones de los datos de una fuente a otra, son menores que los (habitualmente menos tenidos en cuenta) problemas de validez derivados de ciertas «aventuras sociométricas, habituales a la hora de explotar periódicos en el marco de estudios sobre acciones colectivas. Así, cuestionamos usos de la prensa como los consistentes en explotar uno o varios periódicos estatales a lo largo de décadas y, a partir de ese gran corpus de casos recopilados, intentar estimar la variación en la incidencia social real de un tipo de conflicto.

Los cambios de preferencias por parte de los periódicos a la hora de encarar la selección y cobertura de un tipo de sucesos reúnen un notable interés (me atrevería a añadir que son un punto de partida obligado) para quienes investigan sobre protestas sociales. Las variaciones en la «agenda informativa» sobre un tipo de protesta social o conflicto colectivo - los cambios que se han dado en el tratamiento informativo de movilizaciones antigitanas a lo largo de diferentes momentos del posfranquismo, por ejemplo (Río Ruiz, 2005) - nos revelan los posibles cambios que, a su vez, se están produciendo en los niveles de problematización o legitimación social que experimenta un fenómeno, a la vez que nos dan pistas sobre variaciones en las sensibilidades de las audiencias de los medios. Los «ciclos de atención mediática» en torno a un fenómeno de movilización nos ofrecen, en suma, sustantivas pistas sobre posibles variaciones en la estructura de costes y oportunidades políticas en la que se inscribe el mismo.

Sin embargo, los periódicos son un mal instrumento de estimación de las va- 
riaciones reales en la incidencia de diferentes tipos de conflictos a lo largo de un espacio sociohistórico. Poco se puede hacer, además, ante esos problemas. La habitualmente recomendada explotación simultánea de algunos periódicos locales —estrategia costosa, si bien la extensión de la «prensa electrónica» abre hoy nuevas posibilidades de diversificación de los diarios explotables- no garantiza el control de los sesgos asociados a las recolecciones de eventos mediante «el buceo» en diarios estatales, por otro lado los más frecuentemente utilizados para estudiar protestas sociales. La explotación de la prensa local aumenta el catálogo de casos disponibles para nuestros análisis. Pero prensa local y nacional comparten el mismo conjunto de sesgos, relacionados con la lógica de los mass media.

No obstante, también se ha sostenido que no hay porqué desechar el recurso a la prensa para investigar la protesta social. Lo importante será hacer un uso cauto e informado metodológicamente de la misma. La prensa representa con frecuencia el único recurso realista para recopilar y analizar series amplias de eventos dispersos en el tiempo y en el espacio. Se sabe (y este trabajo ha tratado de tenerlo en cuenta) que los periodistas tienden a silenciar ciertos datos sobre ciertos sucesos y a enfatizar otros. Los periódicos, además, pueden diferir notablemente en la exposición de las motivaciones de un suceso, o en la atribución de responsabilidades, tal y como han venido demostrando perspectivas críticas sobre el proceso de producción de noticias, especialmente la «teoría de los encuadres noticiosos». Sin embargo, a pesar de estos problemas apuntados, la prensa nos proporciona una gran cantidad de datos útiles y fiables, en la medida en que están sujetos a pautas estandarizadas e interactivas de cobertura y publicación por parte de los periodistas. Profesionales cuyo margen de manipulación al reportar protestas sociales no es ilimitado, debido a los efectos constrictivos que ejerce el campo periodístico sobre los actores del mismo.

Entre las informaciones más fiables de los periódicos entrarían los datos, casi siempre reseñados en los cuerpos de las noticias, sobre los lugares y factores precipitantes de los conflictos, sobre el carácter planificado o espontáneo de la acción, así como los datos referentes a las pancartas o eslóganes coreados en las protestas. También serían fiables los datos, rara vez omitidos en los relatos periodísticos, sobre las interacciones y divisiones de papeles entre los participantes, así como sobre las tácticas de presión que emplean. Lugares, fechas, interacciones entre actores en la escena de la protesta, tácticas empleadas, secuencias de la movilización, saldos de la acción colectiva, circunstancias precipitantes, eslóganes y consignas son, entre otros datos de sumo interés, circunstancias contempladas de manera rutinaria en la cobertura que hacen los periodistas y sus diarios de las protestas sociales.

En suma, aunque los «hechos» reportados en la prensa pasan indefectiblemente por el «el cedazo y el molinillo de los periodistas», algunos de los datos sobre la protesta social que, de manera rutinaria y sin grandes desviaciones aparecen en los periódicos que cubren tales sucesos, pueden resultarnos muy útiles. Imprescindibles si carecemos de otras fuentes continuadas de registro de su- 
cesos que constituyan alternativas a la prensa La utilidad de estos datos extraídos de periódicos va a depender, no obstante, de la sujeción de quien investigue a unas recomendaciones básicas mediante las cuales podemos maximizar las ventajas de la fuente, e intentar controlar sus distorsiones.

Así, además de explotar (siempre que existan) fuentes complementarias que permitan «triangulaciones», resultará fundamental reducir el alcance de nuestros análisis a un tipo bien delimitado de acción colectiva. A la hora de buscar y catalogar los casos es necesario también operar mediante delimitaciones precisas de las unidades de análisis, así como mediante constructos teóricos bien definidos. Mucho nos jugamos, en consecuencia, en un buen diseño de investigación. Para conseguirlo necesitaremos, antes de sumergirnos en los periódicos, conocer la naturaleza de nuestras fuentes. Este artículo pretendió contribuir a aumentar ese conocimiento metodológico necesario. Si mediante la reflexión y precaución metodológica mejorara nuestro uso de la prensa, evitándonos incurrir en abusos como los señalados en estas páginas, es probable que mejore la «mala prensa» de la que gozan los periódicos en Ciencias Sociales.

\section{BIBLIOGRAFÍA}

AdELL ARGiLÉs, R. (2005): «Manifestómetro: recuento de multitudes y significados de la movilización». Empiria. Revista de metodología de las Ciencias Sociales, núm. 9: 171-208.

BARRANCO, J. y Wisler, D. (1999): «Validaty and Systemacity of Newspaper Data in Event Analysis». European Sociological Review, vol. 15, núm. 3: 301-322.

BouRDIEU, P. (1997): Sobre la televisión. Barcelona: Anagrama.

- (2003): El oficio de científico. Barcelona: Anagrama.

BREED, W. (1955): «Social Control in the Newsroom». Social Forces. núm. 33: 326-335.

Champagne, P. (1999): «La visión mediática», en Bourdieu, P. (dir.). La miseria del mundo. Madrid: Akal.

CHOMSKY, N. (1982): Ilusiones necesarias. Control de pensamiento en las sociedades democráticas. Madrid: Libertarias/Prodhufi.

Cohen, S. y Young, J. (1973): «The Process of Selection», en CoHen, S. y Young, J. (eds.). The Manufacturing of News. Deviance, Social Problems and the Mass Media. Londres: Constable.

CoMBESSIE, J. C. (2000): El método en sociología. Madrid: Alianza.

DANZGER, H. M. (1975): «Validating Conflict Data». American Sociological Review, vol. 40: $570-584$.

ENTMAN, R. (1993): «Framing: Toward a Clarification of a Fractured Paradigm». Journal of Communication, núm. 43 (3): 51-58.

FERNÁNDEZ BARBA, C. (1995): «¿De qué se constituye el habitus en la práctica periodística?». Comunicación y sociedad (DECS, Univ. Guadalajara), núm. 24: 97-125.

FRANZOSI. R. (1987): «The Press as a Source of Sociohistorical Data: Issues in Methodology of Data Collection from Newspapers». Historical Methods, vol. 20, núm. 1: $5-14$.

Fishman, M. (1983): La fabricación de la noticia. Buenos Aires: Edición tres tiempos. 
Gans, H. J. (1979): Deciding what is Notice. A Study of CBS Evenig News, NBC Nightly News, Nesweek and Time. New York: Vintage Books Edition.

GonZÁlez RodríGUEZ, B. (1994): «La utilización de los datos disponibles», en GARCíA FERRANDO, M., IbÁÑ̃EZ, J. y Alvira, F. El análisis de la realidad social. Madrid: Alianza, 245-273.

GurR, T. (1968): «A Causal Model of Civil Strife: A Comparative Analysis Using New Indices». American Political Science Review, núm. 4: 1104-1125.

Hernádez Ramírez, M. H. (1997): «¿Qué son las noticias?», en HeRnÁdez RamíREZ, M. H. (comp.) Sociología del periodismo. Análisis sociológico de la producción de noticias (vol. II). Guadalajara: Universidad de Guadalajara, 9-27.

Hocke, P. (1998): «Determinig the Selection Bias in Local and National Newppaper Reports on Protest Event», en Rucht, D., Koopmans, R. y NeIdHart, F. (eds.). Acts of Dissent: New Developments in the Study of Protest. Sigma: Berlin, 131-163.

Javaloy, F., Rodríguez, A. y EsPelt, E. (2001): Comportamiento colectivo y movimientos sociales. Madrid: Prentice Hall.

Jenkins, C. y Perrow, C. (1977): «Insurgency of the Powerless: Farm Worker Movements: 1946-1972». American Sociological Review, vol. 42: 249-268.

Kielbowicz, R. B. y Scherer, C. (1986): «The Role of the Press in the Dynamics of Social Movements». Research in Social Movements, Conflict and Change, núm. 9: 7196.

Lieberson, S. y Silverman A. R. (1965): «The Precipitants and Underlying Conditions of Race Riots». American Sociological Review, vol. 30: 887-898.

ManN, L. (1974): «Counting the Crowd: Effects of Editorial Policy on Estimates». Journalism Quaterly, núm. 51: 278-285.

McCarthy, J., D. McPhail, C. y Smith, J. (1996): «Images of Protest: Dimension of Selection Bias in Media Coverage of Washington Demostrations, 1982 and 1991». American Sociological Review, vol. 61: 478-499.

Molotch, H. y Lester, M. (1974): «News as a Purposive Behavior. On the Strategic Use of Routine Events, Incidents and Scandals». American Sociological Review, vol. 39: 101-112.

MYERS, D. J. (1997): «Racial Rioting in the 1960S: An Event Historiy Analysis of Local Conditions», American Sociological Review, vol. 62: 92-114.

Myers, D. J. y CAniglia, B. S. (2004): «All the Rioting That's Fit to Print: Selection Effects in National Newspaper Coverage of Civil Disorders», 1968-1969. American Sociological Review, vol. 64: 519-543.

Oliver, P. y Myers, D. J. (1999): «How Events Enter in Public Sphere: Conflict, Location and Spontsorship in Local Newspaper Coverage of Public Events.» American Journal of Sociology, vol. 105, núm. 1: 38-87.

OlzaK, S. (1989): «Analysis of Events in the Study of Collective Action». Annual Review of Sociology, núm, 15: 119-141.

OlzaK, S., Shanahan, S. y West, E. (1994): «School Desegregation, Interracial Exposure and Antibusing Activity in Contemporary Urban American». American Journal of Sociology, vol. 100, núm. 1: 196-214.

Ortega, F. y Humanes, M. L. (2000): Algo más que periodistas. Sociología de una profesión. Barcelona: Ariel.

Paige, J. M. (1975): Agrarian Revolution: Social Movements and Export Agriculture in the Underveloped World. New York: Free Press.

REDONDO, M. (2007): «Un análisis de contenido dual. Propuesta metodológica para el es-

EMPIRIA. Revista de Metodología de Ciencias Sociales. N. ${ }^{\circ}$ 16, julio-diciembre, 2008, pp. 59-84.

ISSN: 1139-5737 
tudio de internet como fuente». Empiria. Revista de metodología de las Ciencias Sociales, núm. 13: 35-58.

Río RuIz, M. A. (2003): Violencia étnica y destierro. Dinámicas de cuatro disturbios antigitanos en Andalucía. Granada: Maristán.

- (2005): Desegregación y conflicto étnico. Un análisis del repertorio de protestas contras las políticas públicas de realojo y escolarización de comunidades gitanas en el posfranquismo. Tesis Doctoral. U. Sevilla (inédita).

Rucht, D. y NeIDHART, F. (1998): «Methodological Issues in Collection Protest Event Data: Unit of Analysis, Sources and Sampling, Coding Problems», en RUCHT, D. y NeIDHART, F. (eds.). Acts of Dissent: New Developments in the Study of Protest. Berlin: Sigma, 65-89.

Skellington, D. (1996): Race in Britain Today. Londres: Sage.

Shalev, M. (1978): «Lies, Damned, and Strike Statistics», en Crouch, C. y Pizzorno, A. The Resurgence of Class Conflict in Western Europe since 1978». London: MacMillan.

SHORTER, E. y Tilly, C. (1985): Las huelgas en Francia. Madrid: Ministerio de Trabajo. SNYDER, D. y Kelly, W. (1977): «Conflict Intensity, Media Sensitivity and the Validaty of Newspaper Data». American Sociological Review, vol. 42: 105-123.

SPILERMAN, S. (1970): «The Causes of Racial Disturbances: A Comparison of Alternative Explanations». American Sociological Review, vol. 35: 627-649.

TARrow, S. (1988): Democracy and Disorder: Politics and Protests in Italy, 1965-1975. New York: Oxford University Press.

- (1997): El poder en movimiento. Los movimientos sociales, la acción colectiva y la política. Madrid: Alianza.

Tilly, C. (1969): «Methods for the Study of Collective Violence», en ConANT, W. R. y Levin, M. A. (eds.). Problems in Research of Community Violence. New York: Praeger.

- (1992): «How Detect, Describe, and Explain Repertoires of Contention». Workings Papers of the Center for Studies of Social Change, New York: New School for Social Research, núm. 143: 1-7 (policopiado).

Tilly, C., Tilly, L. y Tilly, R. (1997): El siglo rebelde, 1830-1930. Zaragoza: Prensas Universitarias de Zaragoza.

TuchMAn, G. (1983): La producción de la noticia. Estudio sobre la producción de la realidad. México D.F.: Gustavo Gili.

VAN DiJK, T. (1992): Racismo y análisis crítico de los medios. Barcelona: Paidós.

WiLKES, R. y RiCARD, D. (2007): «How Does Newspaper Coverage of Collective Action Vary?: Protest by Indigenous People in Canada». The Social Science Journal, vol. 44, núm.2: 231-251.

\section{RESUMEN}

Este artículo resume las ventajas y las limitaciones de la prensa como fuente de datos para estudios sobre protestas sociales y repertorios de acción colectiva. Plantea que uno de los mayores problemas de esta cuestionada fuente remite a la limitada validez externa de los datos obtenidos y a la imposibilidad de determinar la incidencia social real de un fenómeno de movilización mediante la explotación de periódicos. Y ello por mucho que se lleve a cabo, como muchas 
veces se recomienda a fin de mitigar o controlar los sesgos asociados a la fuente, la revisión sistemática de periódicos nacionales, junto a la explotación de prensa local y el «buceo» en otras fuentes continuadas de datos.

En cambio, se defiende que, además de proporcionar un amplio y diversificado catálogo de eventos dispersos en el tiempo y en el espacio, muchos de los datos registrados de manera rutinaria y estandarizada en las noticias que reconstruyen protestas sociales pueden considerarse fiables. Así, tras una sucinta exposición de algunas ventajas de la fuente evaluada, se sostiene que se exagera mucho a la hora de plantear las distorsiones sistemáticas de la «realidad» y de los «hechos» que produce la prensa, si bien la literatura crítica sobre las dinámicas de la producción y selección periodística ha establecido una gama importante de precauciones a tener muy en cuenta al utilizar periódicos como fuente de datos sobre la protesta social.

\title{
PALABRAS CLAVE
}

Análisis de eventos, fuentes de prensa, problemas de fiabilidad y validez

\begin{abstract}
This article summarizes the advantages and limitations of the press as a source of data for studies on social protests and repertoires of collective action. One of he biggest constrains of this questionable source of information is related to the narrow external validity of its data and the impossibility to determine the actual social incidence of a mobilization phenomenon by exploiting newspapers. This is the case even if the press exploitation is combined with a systematic review of national and local newspapers and/or other sources of data, as often recommended to mitigate or control biases associated with this source of information.

On the contrary, this article argues that, in addition to providing a broad and diverse catalog of events scattered in time and space, many of the data routinely and ordinary registered on the news reconstructing social protests can be considered reliable. After briefly presenting some of the advantages of the press, it is argued that the allegations of the press systematically distorting the «facts» and the «reality» are overstated. Nonetheless, the critical literature on journalism production and selection dynamics has established a wide range of precautions to take into account when using newspapers as a source of data on social protests.
\end{abstract}

\section{KEYWORDS}

Events analysis, press sources, reliability and validity problems 